\title{
COMMENT
}

\section{Baiting sharks for marine tourism: Comment on Clua et al. (2010)}

\author{
Juerg M. Brunnschweiler ${ }^{1, *}$, Jonathan McKenzie ${ }^{2}$ \\ ${ }^{1}$ ETH Zurich, Raemistrasse 101, 8092 Zurich, Switzerland \\ ${ }^{2}$ Department of Earth and Environmental Sciences, University of New Orleans, New Orleans, Lousiana 70148, USA
}

\begin{abstract}
A recent study by Clua et al. (2010; Mar Ecol Prog Ser 414:257-266) that looks at the behavioural response of sicklefin lemon sharks Negaprion acutidens to underwater feeding for ecotourism purposes has a number of methodological and semantic problems that complicate the evaluation of the results and raise questions about the conclusions. Main issues are the lack of a control, the use of non-defined terms to characterize observed behaviours, and statements not supported by data. Unwarranted conclusions include the notion that behavioural changes were caused by the human interference, the link between intraspecific aggression and the feeding process, and the loss of genetic variability as a consequence of the aggregating effect of shark feeding.
\end{abstract}

KEY WORDS: Shark feeding • Behaviour · Intraspecific aggression · Marine tourism · Food provisioning

Attracting elasmobranchs with food for the purpose of marine tourism is a highly controversial issue. There is general agreement that feeding or attracting wildlife with food can have a variety of effects (Orams 2002). In the case of sharks, quantifying the magnitude of these effects has proven difficult because critical baseline data remain scarce (Laroche et al. 2007, Meyer et al. 2009). Whereas using biomarkers to measure physiological responses to provisioning-tourism and effects on health is relatively straightforward (Semeniuk \& Rothley 2008, Semeniuk et al. 2009), measuring behavioural responses by directly observing the animals is much more challenging. Clua et al. (2010) have taken on this challenge and present data from a group of sicklefin lemon sharks Negaprion acutidens in the South Pacific. Here we point out fundamental methodological and semantic issues with this study that we think complicate the evaluation of the study's results and raise questions about the conclusions.

(1) The collection of presence/absence, abundance or behavioural data of mobile fish using underwater visual census and observation techniques is prone to bias (Samoilys \& Carlos 2000, Edgar et al. 2004, WardPaige et al. 2010), but this is not acknowledged in Clua et al. (2010). For example, direct observation data of shark behaviour can typically only be collected during a few hours each day, and therefore the majority of the behaviour is not recorded. The use of proxies such as mating scars or bite wounds to measure or quantify behaviour is possible (e.g. Porcher 2005), but relating these proxies with confidence to spatio-temporal causative intra- and interspecific behaviours is challenging, requiring adequate caution when interpreting the results.

(2) The frequent and arbitrary use of non-defined terms is a problem in Clua et al. (2010). Terms such as 'natural behaviour' (p. 257, 258), 'real provisioning' (p. 258), 'atypical dominance behaviour' (p. 262), 'pivotal role' (p. 262), 'exacerbated competition' (p. 263), 'dominant' (p. 263), and 'natural conditions' (p. 263) are neither defined nor referenced. It remains unknown, for example, what the authors consider typical 
dominance behaviour and, as a consequence, irreproducible why an observation should be 'atypical dominance behaviour' (p. 262).

(3) It remains unclear how Clua et al. (2010) measured and quantified 'increased aggression' (p. 262), 'M05, which appeared to be old' (p. 262), 'Since males M07 and M18 were dominant in 2005' (p. 263), and 'Aggression increased significantly' (p. 263) and, if at all, against what baseline they compared their observations.

(4) A fundamental problem in Clua et al. (2010) is the lack of a control. Without a comparable group of sharks that are not being fed the authors cannot postulate with confidence that any observed behavioural changes were caused directly by the human interference.

(5) Several statements and conclusions in Clua et al. (2010) are based on anecdotal observations and not evidenced. (a) There are no data that 'link' intraspecific aggression to the feeding process (p. 263). Therefore, the anecdotal observation of intraspecific aggression cannot be interpreted as 'deviant behaviour' (p. 263). (b) The statement of 'an increase in shark abundance over time' (p. 263) is not supported by results. (c) The authors repeatedly mention that there may be loss of genetic variability as a consequence of the aggregating effect of shark-feeding (p. 263, 264). However, these speculations are unsupported; the data do not address any such link. In fact, the authors themselves state that the number of males decreased during the reproductive season (p. 259), suggesting 'temporary migration for mating with females that do not belong to the studied population' (p. 262).

The debate over baiting sharks for marine tourism is largely based on inference, opinion and anecdote, and therefore research on the effects of food-provisioning tourism is much needed. Thus Clua and his coworkers are to be acknowledged for bringing science to this

Editorial responsibility: Hans-Heinrich Janssen, Oldendorf/Luhe, Germany controversial topic. In our opinion, however, the presentation and discussion of the results in Clua et al. (2010) adds more to the debate than to the objectification of the public discourse.

\section{LITERATURE CITED}

Clua E, Buray N, Legendre P, Mourier J, Planes S (2010) Behavioural response of sicklefin lemon sharks Negaprion acutidens to underwater feeding for ecotourism purposes. Mar Ecol Prog Ser 414:257-266

Edgar GJ, Barrett NS, Morton AJ (2004) Biases associated with the use of underwater visual census techniques to quantify the density and size-structure of fish populations. J Exp Mar Biol Ecol 308:269-290

Laroche RK, Kock AA, Dill LM, Oosthuizen WH (2007) Effects of provisioning ecotourism activity on the behaviour of white sharks Carcharodon carcharias. Mar Ecol Prog Ser 338:199-209

Meyer CG, Dale JJ, Papastamatiou YP, Whitney NM, Holland KN (2009) Seasonal cycles and long-term trends in abundance and species composition of sharks associated with cage diving ecotourism activities in Hawaii. Environ Conserv 36:104-111

Orams MB (2002) Feeding wildlife as a tourism attraction: a review of issues and impacts. Tour Manage 23:281-293

Porcher IF (2005) On the gestation period of the blackfin reef shark, Carcharhinus melanopterus, in waters off Moorea, French Polynesia. Mar Biol 146:1207-1211

Samoilys MA, Carlos G (2000) Determining methods of underwater visual census for estimating the abundance of coral reef fish. Environ Biol Fishes 57:289-304

Semeniuk CAD, Rothley KD (2008) Costs of group-living for a normally solitary forager: effects of provisioning tourism on southern stingrays Dasyatis americana. Mar Ecol Prog Ser 357:271-282

Semeniuk CAD, Bourgeon S, Smith SL, Rothley KD (2009) Hematological differences between stingrays at tourist and non-visited sites suggest physiological costs of wildlife tourism. Biol Conserv 142:1818-1829

Ward-Paige C, Mills Flemming J, Lotze HK (2010) Overestimating fish counts by non-instantaneous visual censuses: Consequences for population and community descriptions. PLoS ONE 5:e11722

Submitted: October 11, 2010; Accepted: November 19, 2010

Proofs received from author(s): November 30, 2010 